\title{
Establishment of indirect immunofluorescence assay for rotavirus
}

\author{
J. TAO ${ }^{1}$, J. ZHANG ${ }^{1}$, X. LIU ${ }^{1}$, H. JIN ${ }^{1}$, C. JIANG ${ }^{1,2}$, Y. YIN ${ }^{1 *}$ \\ ${ }^{1}$ School of Chemistry and Life Science, Changchun University of Technology, Changchun 130012, P. R. China; ${ }^{2}$ National Engineering \\ Laboratory for AIDS Vaccine, School of Life Science, Jilin University, Changchun 130012, P. R. China
}

Received February 12, 2015; revised July 7, 2015; accepted February 19, 2016

\begin{abstract}
Summary. - Rotavirus infection is the most frequent cause of infantile gastroenteritis worldwide and a significant cause of death in infants and young children, following severe diarrhea and dehydration. Rotavirus vaccines are considered the most effective way to prevent rotavirus infections. In the process of developing rotavirus vaccines, it is crucial to establish a reliable and standardized method to determine vaccine titer. In this study, we developed an indirect immunofluorescence assay (IFA) to determine the infectious titer of Lanzhou lamb rotavirus (LLR) vaccine grown in MA104 cells. The activating concentration of trypsin was $1 \mu \mathrm{g} / \mathrm{ml}$ for healthy monolayers of MA104 cells at $100 \%$ confluence. After incubation for $18 \mathrm{hr}$, a rabbit anti-SA11 polyclonal antibody, diluted at 1:800 in PBS, was added to all wells, followed by an Alexa-488-conjugated secondary antibody diluted at 1:500 in PBS. Cells were examined with a fluorescence microscope. Our results show that IFA was more reproducible, more sensitive, simpler, and more rapid than the $\log 50 \%$ cell culture infectious doseELISA ( $\operatorname{lgCCID}{ }_{50}$-ELISA) in measuring the rotavirus vaccines. IFA provided a reliable basis for the qualitative and quantitative analysis of rotavirus, and the certification of rotavirus vaccine production.
\end{abstract} ELISA

Keywords: rotaviruses; diarrhea and dehydration; titration; indirect immunofluorescence assay; $\operatorname{lgCCID}{ }_{50}{ }^{-}$

\section{Introduction}

Group A rotaviruses, in the family Reoviridae, are the leading cause of childhood gastroenteritis, accounting for over 453,000 deaths annually in children worldwide, with 95\% of these occurring in developing countries (Tate et al., 2012). The mature rotavirus consists of a triple-layered icosahedral capsid that encompasses a genome consisting of 11 segments of double-stranded RNA (Coste et al., 2000). The innermost core of rotavirus is composed of VP2, which forms a protein layer that surrounds two minor proteins, VP1 and VP3, and the genome. This inner core layer is surrounded by the major capsid protein VP6 and constitutes

”E-mail: 732450624@qq.com; phone: +0086-18743024507. Abbreviations: $\mathrm{CPE}=$ cytopathic effect; $\mathrm{CV}=$ coefficient of variation; FCFU = fluorescent cell forming units; IFA $=$ indirect immunofluorescence assay; $\operatorname{lgCCID}{ }_{50}$-ELISA $=\log 50 \%$ cell culture infectious dose-ELISA; LLR = Lanzhou lamb rotavirus transcriptionally active double-layered particles (Zeng et al., 1998). Rotaviruses are classified into various major groups based on the middle-layer VP6 protein, and further classification within each group is based on the outer coat proteins VP7 and VP4 (Estes and Cohen, 1989). VP4 and VP7 are neutralization antigens and play important roles in virus entry into the target cells and subsequent infection (Aguirre et al., 2008; Martella et al., 2010).

RV5, licensed in the United States in 2006, is a live, oral vaccine that contains five reassortant rotaviruses developed from human and bovine parental rotavirus strains (Heaton et al., 2005). Four reassortant rotaviruses express one of the four outer capsid proteins (G1, G2, G3, or G4) from the human rotaviral parental strains and the attachment protein (P7 [5]) from the bovine rotavirus parental strain. The fifth reassortant virus expresses the attachment protein (P1A [8]) from the human rotavirus parental strain and the outer capsid protein G6 from the bovine rotavirus parental strain (Cortese and Parashar, 2009). The LLR vaccine is manufactured by the Lanzhou Institute of Biological 
Products, Lanzhou, China, and consists of the monovalent serotype $(\mathrm{P}[12] \mathrm{G}[10])$, group A, which was isolated in 1985 from a local lamb with diarrhea and grown in primary calf kidney cells. This vaccine has only been used in China (Fu et al., 2007; 2012).

There is currently no specific treatment for rotavirus diseases, and vaccination has become the most efficient way to prevent and control outbreaks of the disease. All rotavirus vaccines currently in use are live vaccines. Therefore, in order to ensure an efficient immune response, accurate and rapid determination of the rotaviral titer is important in the process of developing a rotavirus vaccine. Various methods have been developed to measure the rotavirus titers, including the plaque assay (Ranheim et al., 2006), the TCID $_{50}$ (virus concentration, at which $50 \%$ of infected cultures show substantial cytopathology; based on end-point serial dilutions) assay, the reverse transcription-quantitative PCR (RT-qPCR) (Mukhopadhya et al., 2013) and $\operatorname{lgCCID}_{50}$-ELISA. The potency of live virus vaccines has traditionally been determined with the plaque and $\mathrm{TCID}_{50}$ assays, which quantify the infectious virus (Gaush and Smith, 1968; Smith et al., 1979; Sood et al., 1995). These assays are typically highly variable, labor intensive, and time consuming. Detecting rotavirus vaccine by these methods will take several days or even one week for the cytopathology to become apparent. Ranheim et al. (2006) established a sensitive and reproducible method to determine the in vitro infectious potency of a pentavalent reassortant rotavirus vaccine (RotaTeq ${ }^{\varpi}$, Merck KgaA, Darmstadt, Germany) as an alternative to classical potency assays. Potency was determined by assaying cellbased viral replication, followed by RT-qPCR analysis. The Rotarix ${ }^{\oplus}$ vaccine (GlaxoSmithKline, Brentford, UK) was the first vaccine to be detected with a type-specific anti-VP7 antibody, followed by a peroxidase-conjugated secondary antibody, and the addition of a chromogenic substrate. For the $\operatorname{lgCCID}{ }_{50}$-ELISA, the LLR was detected with an ELISAbased antigen diagnostic kit (Lanzhou Institute of Biological Products, Lanzhou, China). The samples were repeatedly frozen and thawed to identify negative and positive samples, and viral titer was calculated with the Karber method (Kou et al., 2012). The limitation of this method is that the results can be affected by various elements in the ELISA kit, including the concentration of the enzymes. Despite their respective advantages, these aforementioned methods have their limitations in quantifying rotaviral titers. On the other hand, the IFA technique has been used extensively for the detection and quantitation of viruses, including infectious pancreatic necrosis virus (Kuen-Ching et al., 1974). In this study, we established an IFA to detect rotavirus using a rabbit polyclonal primary antibody directed against SA11 and an Alexa-488-labeled goat anti-rabbit IgG secondary antibody to provide a sensitive, accurate, and rapid method for the quantitative analysis of rotavirus vaccines. We also com- pared the IFA and $\operatorname{lgCCID}_{50}$-ELISA methods for assaying rotavirus vaccines.

\section{Materials and Methods}

Cell culture and viral strains. MA104 cells were grown in Dulbecco's modified Eagle's medium (DMEM; Sigma-Aldrich, St. Louis, MO, USA) supplemented with 10\% fetal bovine serum (Hyclone, Victoria, Australia), $100 \mathrm{U} / \mathrm{ml}$ penicillin, and $10 \mu \mathrm{g} / \mathrm{ml}$ streptomycin. For the virus assays, the cells were cultured in 96-well plates. LLR was provided by Lanzhou Institute of Biological Products.

Optimization of IFA. A. Cell seeding density: 96 -well plates were seeded with $1 \times 10^{4}$ cells/well, $1.5 \times 10^{4}$ cells/well, $2 \times 10^{4}$ cells/well, or $2.5 \times 10^{4} \mathrm{cells} /$ well. Cells were allowed to grow in a tissue culture incubator at $37^{\circ} \mathrm{C} 5 \% \mathrm{CO}_{2}$. When the cells were $100 \%$ confluent and healthy, the growth medium was removed and the monolayer washed twice with PBS (Gibco, Life Technologies, Carlsbad, CA, USA). The MA104 cell monolayers required 3-4 days to reach confluence in the 96-well plates. $\underline{B}$. Trypsin concentration: DMEM $(50 \mu \mathrm{l})$ with various final concentrations of trypsin (DMEM-T, Invitrogen) was added to all the wells in 96-well plates and aliquots of the rotavirus were digested for $30 \mathrm{~min}$ at $37^{\circ} \mathrm{C}$. Various final concentrations of trypsin $(0.5,1.0$, or $1.5 \mu \mathrm{g} / \mathrm{ml})$ were used to activate the infectivity of the rotavirus. After adding $50 \mu \mathrm{l}$ of DMEM-T to all the wells in a 96-well tray, $50 \mu \mathrm{l}$ of each virus sample was added to the first row of the wells. The mixture was serially diluted twofold across the plate using a multichannel pipette by transferring $50 \mu \mathrm{l}$ from the first well and diluting it with the same volume of medium in the adjacent well. The dilution procedure was repeated for all but the last row of wells. The last row of wells was used for the diluent controls. After incubation, a further $50 \mu \mathrm{l}$ of DMEM with various concentrations of trypsin was added to each well and incubated for different times $(12,18,24$, or $36 \mathrm{hr})$ at $37^{\circ} \mathrm{C} 5 \% \mathrm{CO}_{2}$. C. Fixation methods: After the supernatant was gently aspirated from each well with a vacuum pump and any excess was removed by gently blotting the sample with an absorbent paper towel, the different concentrations of Acetone and paraformaldehyde were added for fixation. The cells were fixed with $150 \mu \mathrm{l}$ of $80 \%$ acetone (v/v), 100\% paraformaldehyde, or $90 \%$ paraformaldehyde in PBS at room temperature for $5 \mathrm{~min}, 10 \mathrm{~min}$, or $15 \mathrm{~min}$. Acetone and paraformaldehyde was discarded and samples air-dried until no acetone was detected. D. Antibody concentration: Rabbit anti-SA11 polyclonal antibody (Murdoch Childrens Research Institute, Australia) was diluted at 1:800 in PBS and added to all the wells at 50 $\mu \mathrm{l} /$ well and incubated at $37^{\circ} \mathrm{C}$ for $1 \mathrm{hr}$. The antibody solution was removed and the wells washed twice with $150 \mu$ PBS. Excess PBS was removed by inverting the plate and blotting onto an absorbent paper towel. Alexa-488-conjugated secondary antibody (Murdoch Childrens Research Institute, Australia) diluted at 1:500 in PBS was added to all the wells at $30 \mu \mathrm{l} /$ well, and the samples were incubated at $37^{\circ} \mathrm{C}$ for $1 \mathrm{hr}$. The secondary antibody solution was removed and the cells washed twice with PBS. Excess PBS was removed and the 
Table 1. Effect of cell density at the time of infection on rotaviral titers in a 96-well plate (the rotavirus titer (per $\mathrm{ml}$ of medium) was determined $18 \mathrm{hr}$ after infection)

\begin{tabular}{cccc}
\hline \multirow{2}{*}{ Experiment No. } & \multicolumn{2}{c}{ Different cultivation conditions for rotavirus titers (FCFU/ml) } \\
\cline { 2 - 4 } & $\mathbf{1} \times \mathbf{1 0}^{4}$ cells/well & $\mathbf{1 . 5} \times \mathbf{1 0}^{4}$ cells/well & $\mathbf{2} \times \mathbf{1 0 ^ { 4 }}$ cells/well \\
\hline 1 & $0.93 \times 10^{6}$ & $1.03 \times 10^{6}$ & $1.77 \times 10^{6}$ \\
2 & $1.03 \times 10^{6}$ & $1.18 \times 10^{6}$ & $1.66 \times 10^{6}$ \\
3 & $1.23 \times 10^{6}$ & $1.30 \times 10^{6}$ cells/well & $1.57 \times 10^{6}$ \\
\hline
\end{tabular}

plate was allowed to dry. To optimize the dilution of the primary and secondary antibodies, dilutions of 1:500, 1:800 and 1:1000 for rabbit anti-SA11 polyclonal antibody, and 1:250, 1:500 and 1:800 for Alexa-488 labeled goat anti-rabbit IgG antibody were tested. Cells infected with LLR were used as the positive control and uninfected cells as the negative control.

Counting fluorescent cells. Fluorescent cells were examined at $\times 10$ magnification with a fluorescence microscope (Nikon, DSU2) by focusing on the cell monolayer. The MA104 monolayer was examined for intracytoplasmic fluorescence by scanning from the top to the bottom of the well. The infective titer was determined by counting the number of fluorescent cell-forming units per $\mathrm{ml}$ (FCFU/ml) from plates containing 50-100 FCFU. Fluorescent cells in the next adjacent well were also counted to confirm the success of the serial dilution. Virus titer was determined as: $\mathrm{FCFU} / \mathrm{ml}=$ No. fluorescent cells $\times$ No. fields $(2.4) \times$ dilution factor $\times$ samples of conversion factor to $\mathrm{ml}(20)$.

Sensitivity test for IFA. To determine the feasibility of IFA, sensitivity test was carried out. When the MA104 cells formed a $100 \%$ confluent monolayer, the supernatant was discarded, and the rotavirus strain LLR $\left(1 \times 10^{6} \mathrm{FCFU} / \mathrm{ml}\right)$ diluted to $10^{-1}, 10^{-2}$, $10^{-3}, 10^{-4}$, and $10^{-5}$ with DMEM was added. A positive control group and an uninfected negative control group were prepared in parallel 96-well plates. All samples were incubated in a $37^{\circ} \mathrm{C} / 5 \%$ $\mathrm{CO}_{2}$ incubator. The titers were measured with IFA using the optimal conditions determined above after incubation for $18 \mathrm{hr}$.

Evaluation of the reproducibility of IFA. Nine plates of MA104 cells monolayers were cultured at the same time, but in different laboratories. Each sample was inoculated with $50 \mu \mathrm{l}$ of LLR for IFA. After incubation at $37^{\circ} \mathrm{C}$ under $5 \% \mathrm{CO}_{2}$ for $18 \mathrm{hr}$, the cultures were stained and the fluorescent cells in each well of the 96-well plates were counted.

\section{Results}

\section{Effects of MA104 cell density on viral titers}

The effects of cell density were evaluated by seeding different densities of cells from the same batch in a 96-well plate. The rotaviral titer was determined $18 \mathrm{hr}$ after infection by IFA under the same assay conditions. As shown in Table 1, rotavi-
Table 2. The mean titers of LLR after treatment with different concentrations of trypsin

\begin{tabular}{lccc}
\hline \multirow{2}{*}{ Sample } & \multicolumn{3}{c}{ Trypsin concentrations (FCFU/ml) } \\
\cline { 2 - 4 } & $\mathbf{0 . 5} \mu \mathbf{g} / \mathbf{m l}$ & $\mathbf{1} \mu \mathbf{g} / \mathbf{m l}$ & $\mathbf{1 . 5} \mu \mathbf{g} / \mathbf{m l}$ \\
\hline LLR & $1.42 \times 10^{6}$ & $1.75 \times 10^{6}$ & $1.56 \times 10^{6}$ \\
\hline
\end{tabular}

rus propagation was hampered at densities of $1 \times 10^{4}$ cells/well, $1.5 \times 10^{4}$ cells/well, and $2.5 \times 10^{4}$ cells/well, and the optimal cell density was $2 \times 10^{4}$ cells/well. The experiments were repeated three times, and the optimal rotaviral titer was obtained with cultures seeded at $2 \times 10^{4}$ cells/well. The difference in viral titers in response to cell density was possibly due to factors such as cell-cell contact inhibition, nutrient limitation, and the presence of metabolic waste products.

\section{Effects of trypsin on viral titers}

The infectivity of rotaviruses might be affected by trypsin treatment. To determine the effects of trypsin on rotaviral growth and titers, the mean titers of LLR in three groups of experiments after treatment with different concentrations of trypsin were calculated (Table 2). Confluent monolayers of MA104 cells in 96-well plates were inoculated with the activated virus, and the virus was harvested to determine the LLR titer $18 \mathrm{hr}$ after infection. As shown in Table 2, the maximum LLR titer was obtained after activation with $1 \mu \mathrm{g} / \mathrm{ml}$ trypsin.

\section{Optimal time after infection for IFA staining}

The effect of different infection times on the viral titer measured by IFA was evaluated. Uninfected cells were used as the blank control. Virus had an obvious cytopathic effect (CPE) on cells $18 \mathrm{hr}$ after inoculation (Fig. 1). To measure the apoptotic status of MA104 cells after infection and assess the effects of different infection times, the viral titers were measured with IFA. The experiments were repeated three times. As shown in Table 3, MA104 cells infected with strain LLR showed gradual increase of virus titer from 12 to $36 \mathrm{hr}$ after infection. 

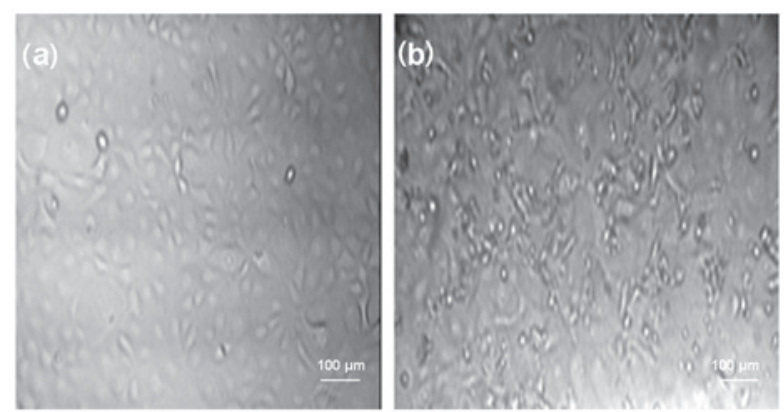

Fig. 1

Effects of MA104 cell density on viral titers

(a) Uninfected cells as the blank control. (b) Obvious CPE was observed in cell culture at $18 \mathrm{hr}$ after inoculation.

\section{Fixative and fixation times for IFA}

The medium was removed and the cells were rinsed with PBS and fixed with different volumes of acetone or paraformaldehyde for different times at room temperature. The exfoliated cytology, mean fluorescence intensity to number of fluorophores per cell, and the optical clarity of the fluorescent images acquired with IFA were compared between different fixation conditions. $80 \%$ acetone was chosen as the fixative and a fixation time of $10 \mathrm{~min}$ at room temperature was selected.

\section{Indirect immunofluorescent staining of infected cells}

After the infected cells were fixed in acetone for $10 \mathrm{~min}$ and air-dried, the primary and secondary antibodies were added to each well. Under the optimal conditions, specific fluorescence was only visible in the cytoplasm of the infected
Table 3. Titers of LLR at different times after infection determined with IFA

\begin{tabular}{ccccc}
\hline \multirow{2}{*}{ Trial No. } & \multicolumn{4}{c}{ Infection time (FCFU/ml) } \\
\cline { 2 - 5 } & $\mathbf{1 2 ~ h r}$ & $\mathbf{1 8} \mathbf{~ h r}$ & $\mathbf{2 4} \mathbf{h r}$ & $\mathbf{3 6 ~ h r}$ \\
\hline 1 & $0.76 \times 10^{6}$ & $1.71 \times 10^{6}$ & $1.76 \times 10^{6}$ & $1.88 \times 10^{6}$ \\
2 & $0.71 \times 10^{6}$ & $1.75 \times 10^{6}$ & $1.78 \times 10^{6}$ & $1.81 \times 10^{6}$ \\
3 & $0.76 \times 10^{6}$ & $1.73 \times 10^{6}$ & $1.73 \times 10^{6}$ & $1.85 \times 10^{6}$ \\
\hline
\end{tabular}

cells but not in uninfected cells (Fig. 2). The optimal primary antibody and secondary antibody dilutions were 1:800 and 1:500, respectively, based on the observed numbers of positive cells and the variations in the specific fluorescence intensity.

\section{Sensitivity test for IFA}

To ensure that IFA was accurate and applicable under optimal conditions, its sensitivity in detecting LLR strains was investigated for each dilution. Samples were prepared at an initial titer of $1 \times 10^{6} \mathrm{FCFU} / \mathrm{ml}$ and serially diluted to $10 \mathrm{FCFU} / \mathrm{ml}$ to assess the sensitivity by IFA. As shown in Fig. 3, IFA was sufficiently sensitive to detect rotavirus at $10 \mathrm{FCFU} / \mathrm{ml}$.

\section{Reproducibility of IFA}

To determine the reproducibility of IFA, the experiment using rotavirus strain LLR was repeated nine times. As shown in Table 4, the coefficient of variation (CV) for the viral titers of the rotavirus vaccine was $2.6 \%$, indicating very high repeatability of the IFA.
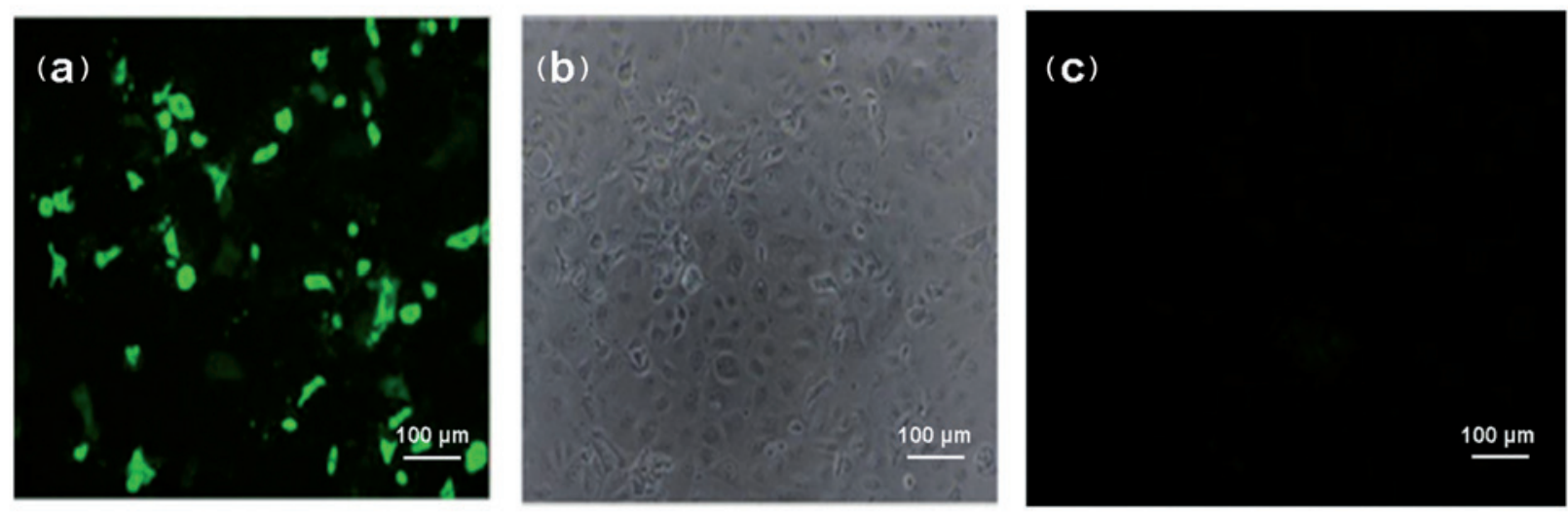

Fig. 2

Optimal dilution of the primary and secondary antibodies for IFA

(a) Strong immunofluorescent staining of LLR was observed when the primary and secondary antibodies were diluted at 1:800 and 1:500, respectively. (b) No addition of the primary and secondary antibody. (c) Negative control. 

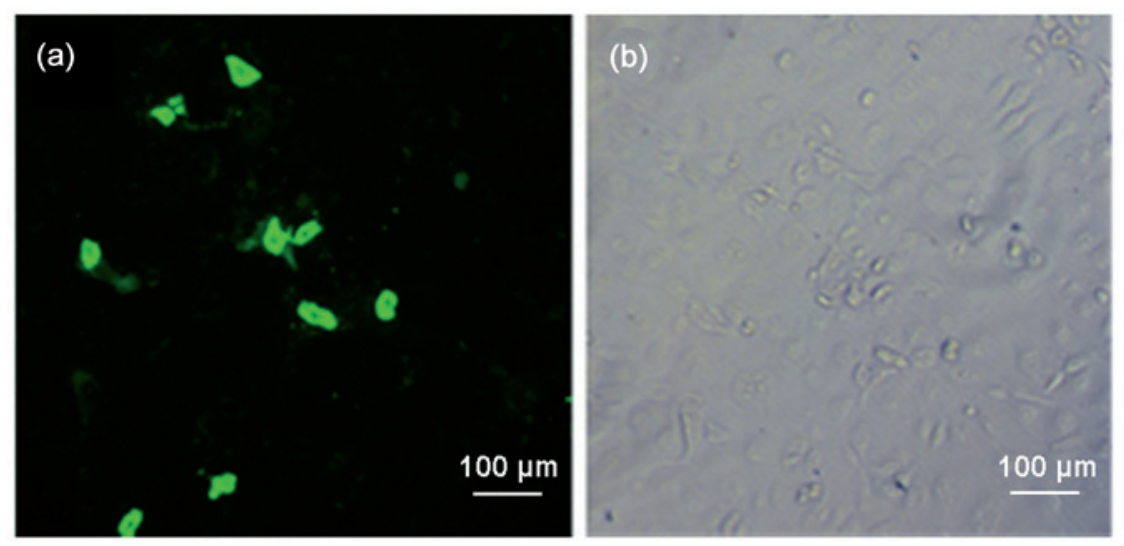

Fig. 3

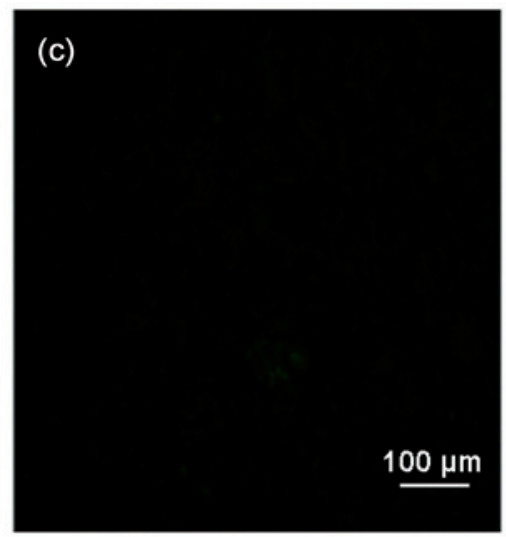

$\underline{00 \mu \mathrm{m}}$

Sensitivity test for IFA

Samples were prepared at an initial titer of $1 \times 10^{6} \mathrm{FCFU} / \mathrm{ml}$ and serially diluted to $10 \mathrm{FCFU} / \mathrm{ml}$. (a) Immunofluorescent staining of LLR. (b) No primary and secondary antibody. (c) Negative control.

Table 4. Viral titers for LLR measured from nine repeated experiments

\begin{tabular}{ccc}
\hline Sample No. & Viral titers (FCFU/ml) & CV (\%) \\
\hline 1 & $1.74 \times 10^{6}$ & \\
2 & $1.76 \times 10^{6}$ & \\
3 & $1.73 \times 10^{6}$ & \\
4 & $1.74 \times 10^{6}$ & $2.6 \%$ \\
5 & $1.81 \times 10^{6}$ & \\
6 & $1.77 \times 10^{6}$ & \\
7 & $1.68 \times 10^{6}$ & \\
8 & $1.81 \times 10^{6}$ & \\
9 & $1.69 \times 10^{6}$ \\
\hline
\end{tabular}

\section{Discussion}

This study was designed to establish an IFA to detect the titer of rotavirus strain LLR. The greatest advantage of IFA compared with the plaque and $\operatorname{lgCCID}_{50}$ assays is the short time required. The IFA test takes $24 \mathrm{hr}$, whereas the plaque assay and TCID $_{50}$ assay take about seven days (Wang et al., 2012). In previous studies, the potency of the pentavalent reassortant rotavirus vaccine ( RotaTeq $^{\circledast}$ ) was determined by measuring the cell-based viral replication, followed by an RT-qPCR analysis. However, this method requires expensive reagents and equipment, causes variation in results, and carries the risk of cross contamination. In addition, the $\operatorname{lgCCID}_{50}$-ELISA technique requires 5-7 days after infection to determine the viral titer. In contrast, the IFA was more reproducible and faster. Many previous studies have shown that the IFA method is repeatable, sensitive, simple, and rapid in detecting the titer of rotavirus. This method can be applied to not only strain LLR but also to the strains RV3 and RV5 (data not shown).
It is critical to optimize the conditions for IFA. In this study, the optimal cell density for MA104 cells, the optimal trypsin concentration required to activate rotaviral infectivity, the best time to fluorescently stain the infected MA104 cells, the best method of fixation, and the best dilution for the primary and secondary antibodies were determined. No previous studies have investigated the relationship between rotaviral titers and cell concentrations for IFA. We have found that it is important to seed cells sparsely and allow them to grow for several days before inoculating them with the LLR. The optimal rotavirus titer for staining LLR was obtained at a seeding density of $2 \times 10^{4}$ cells/well. In this study, the incubation of cells and the activation of virus were carried out in a single plate.

The trypsin treatment prior to infection was a routine procedure during the measurement of rotaviral titers. The spike protein VP4 is important in determining the host cell tropism, virulence, and viral attachment and penetration (Kirkwood et al., 1998). Cleavage of VP4 enhances viral infectivity (Espejo et al., 1981; Estes et al., 1981). It is known that the infectivity of rotaviruses is increased by, and is probably dependent upon, treatment of the virus with trypsin. This proteolytic treatment results in the specific cleavage of VP4 to polypeptides VP8 $(28 \mathrm{kDa})$ and VP5 $(60 \mathrm{kDa})$, which represent the amino- and carboxyterminal regions of the protein, respectively (Arias et al. 1996). In this study, the titer of rotavirus was affected by the trypsin concentration used for virus activation. The maximum titer of LLR was obtained after activation with $1 \mu \mathrm{g} / \mathrm{ml}$ trypsin. In contrast, the mean titer of LLR was lower after activation with a trypsin concentration of $0.5 \mu \mathrm{g} / \mathrm{ml}\left(1.42 \times 10^{6} \mathrm{FCFU} / \mathrm{ml}\right)$ or $1.5 \mu \mathrm{g} /$ $\mathrm{ml}\left(1.56 \times 10^{6} \mathrm{FCFU} / \mathrm{ml}\right)$, indicating that neither $0.5 \mu \mathrm{g} / \mathrm{ml}$ nor $1.5 \mu \mathrm{g} / \mathrm{ml}$ trypsin is conducive to cleavage of VP4 and viral propagation. 
It is also important to determine the best time after infection to stain the infected cultures using IFA as the appearance of viral antigen is not uniform in all cells. If stained too early after infection, some of the infected cells will not fluoresce. On the other hand, if stained too late after infection, cells from the second cycle of infection may be stained, or cells from the first cycle of infection may have lost the antigen and will not be stained. $18 \mathrm{hr}$ was chosen as the best time of LLR infection in MA104 cells to both save time and avoid the second cycle of viral infection. $18 \mathrm{hr}$ was long enough for the rotavirus to replicate in the cells without destroying them.

The fixation of cells is also a crucial step in IFA, allowing the cells to be observed with a fluorescence microscope. If the virus replication in the cells is diffused or the immune activity of the virus is lost, the test will ultimately be invalid. In this study, the appropriate fixative and fixation time was chosen based on the nature of the antigen, the antibody characteristics, and the cell type. No single fixative is ideal for all cells, samples, or antigens. Therefore, each fixation procedure must be optimized to balance adequate fixation while not disturbing the endogenous location of the rotavirus strain LLR and the cell morphology. Based on the presence of exfoliated cells and the specific fluorescence intensity and clarity, $80 \%$ cold acetone was chosen as the fixative with a fixation time of $10 \mathrm{~min}$. Under these conditions, the activity of the viral antigen is maintained for a long time, and antibody has free access to all the cells and all the subcellular locations of the antigen.

In this study, optimal working dilutions of the primary and secondary antibodies were determined based on the specific fluorescence intensities and the numbers of positive cells. Dilutions of the primary antibody in the range of 1:500-1:1000 and the secondary antibody in the range of 1:250-1:800 produced fluorescence. Primary antibody at 1:800 and secondary antibody at 1:500 most effectively differentiated the specific fluorescence and background fluorescence, with minimum nonspecific background staining.

The accuracy and repeatability are essential for a quantitative test. Our results indicate that the sensitivity of the assay was improved by optimizing the experimental conditions. Using IFA, it's easy to detect a sample when the viral titer was diluted from $1 \times 10^{6} \mathrm{FCFU} / \mathrm{ml}$ to $10 \mathrm{FCFU} / \mathrm{ml}$. In comparison, the $\operatorname{lgCCID}{ }_{50}$-ELISA method couldn't detect $10^{2}$ virus particles per milliliter (Luo, 2009). These results indicate that IFA was 10 times more sensitive than the $\operatorname{lgCCID}_{50}$-ELISA method for assaying the LLR. When the samples were diluted from $1 \times 10^{6} \mathrm{FCFU} / \mathrm{ml}$ to $10 \mathrm{FCFU} / \mathrm{ml}$, there was a linear relationship between the total number of fluorescent cells and the dilution ratio for rotavirus LLR. In addition, the CVs for IFA and $\operatorname{lgCCID}{ }_{50}$-ELISA were $2.6 \%$ and $11.48 \%$ (Luo, 2009), respectively, indicating that the reproducibility of IFA was higher than that of the $\operatorname{lgCCID}_{50}$-ELISA in determining rotaviral titers. Based on its high sensitivity, simple opera- tion, rapid detection, low cost, and other advantages, IFA will become the most widely used technique for detecting rotavirus vaccines.

In summary, we developed a sensitive and repeatable IFA to quantify rotavirus using a rabbit polyclonal antibody directed against SA11 as the primary antibody and an Alexa-488-labeled goat anti-rabbit IgG antibody as the secondary antibody. This method showed great prospects and provided a reliable basis for the qualitative and quantitative analysis of rotavirus and certifying the production of rotavirus vaccine.

Acknowledgements. The research was supported by Changchun BCHT Biotechnology Co. We would like to acknowledge the outstanding technical assistance provided by Yin Yuhe and Jiang Chunlai. We thank Ren Hui for manuscript editing. We also offer our gratitude to Changchun University of Technology and Jilin University for assistance in manuscript preparation.

\section{References}

Aguirre IG, Steyer A, Boben J, Gruden K, Prijatelij MP, Ravnikar M (2008): Sensitive detection of multiple rotavirus genotypes with a single reverse transcription-real-time quantitative assay. J. Clin. Microbiol. 46, 2547-2554. http://dx.doi. org/10.1128/JCM.02428-07

Arias CF, Romero P, Alvarez V, López S (1996): Trypsin activation pathway of rotavirus infectivity. J. Virol. 70, 5832-5839.

Cortese MM, Parashar UD (2009): Prevention of rotavirus gastroenteritis among infants and children recommendations of the advisory committee on immunization practices (ACIP). MMWR Recomm. Rep. 58, 1-25.

Coste A, Sirard J-C, Johansen K, Cohen J, Kraehenbuhl J-P (2000): Nasal immunization of mice with virus-like particles protects offspring against rotavirus diarrhea. J. Virol. 74, 8966-8971. http://dx.doi.org/10.1128/JVI.74.19.8966$\underline{8971.2000}$

Espejo RT, Lopez S, and Arias C (1981): Structural polypeptides of simian rotavirus SA11 and the effect of trypsin. J. Virol. $37,156-160$

Estes MK, Graham DY, Mason BB (1981): Proteolytic enhancement of rotavirus infectivity: molecular mechanisms. J. Virol. 39, 879-888.

Estes MK, Cohen J (1989): Rotavirus gene structure and function. Microbiol. Rev. 53, 410-449.

Fu C, Wang M, Liang J, He T, Wang D, Xu J (2007): Effectiveness of Lanzhou lamb rotavirus vaccine against rotavirus gastroenteritis requiring hospitalization: a matched case-control study. Vaccine 25, 8756-8761. http://dx.doi.org/10.1016/j. vaccine.2007.10.036

Fu C, He Q, Xu J, Xie H, Ding P, Hu W, Dong Z, Liu X, Wang $M$ (2012): Effectiveness of the Lanzhou lamb rotavirus vaccine against gastroenteritis among children. Vaccine 31, 154-158. http://dx.doi.org/10.1016/j. vaccine.2012.10.078 
Gaush CR, Smith TF (1968): Replication and plaque assay of influenza virus in an established line of canine kidney cells. App. Microbiol. 16, 588-594.

Heaton PM, Goveia MG, Miller JM, Offit P, Clark HF (2005): Development of a pentavalent rotavirus vaccine against prevalent serotypes of rotavirus gastroenteritis. J. Infect. Dis. 192, 17-21. http://dx.doi.org/10.1086/431500

Mukhopadhya I, Sarkar R, Menon VK, Babji S, Paul A, Rajendran P, Sowmyanarayanan TV, Moses PD, Iturriza-Gomara M, Gray JJ, Kang G (2013): Rotavirus shedding in symptomatic and asymptomatic children using reverse transcription-quantitative PCR. J. Med. Virol. 85, 1661-1668. http://dx.doi.org/10.1002/jmv.23641

Kirkwood CD, Bishop RF, Coulson BS (1988): Attachment and growth of human rotaviruses RV-3 and S12/85 in Caco-2 cells depend on VP4. J. Virol. 72, 9348-9352.

Kou GY, Yu L, Zhu CF, Wang MQ, Zhou X (2012): Development and application of limiting dilution method for screening rotavirus LD9. Chin. New Drug J. 21, 1135-1139.

Kuen-Ching TU, Spendlove RS, Goede RW (1974): Immunofluorescent cell assay of infectious pancreatic necrosis virus. Appl. Microbiol. 27, 593-599.

Luo C (2009): A credible and stable standardized test method for rotavirus vaccine's viral titers. CNKI, China, pp. 1-54.

Martella V, Bányai K, Buonavoglia C, Matthijnssens J, Ciarlet M (2010): Zoonotic aspects of rotaviruses. Vet. Microbiol. 140, 246-255. http://dx.doi.org/10.1016/j. vetmic.2009.08.028
Ranheim T, Mathis PK, Joelsson DB, Smith ME, Campbell KM, Lucas G, Barmat S, Melissen E, Benz R, Lewis JA, Chen J, Schofield T, Sitrin RD, Hennessey JP Jr (2006): Development and application of a quantitative RT-PCR potency assay for a pentavalent rotavirus vaccine (RotaTeq). J. Virol. Methods 131, 193-201. http://dx.doi.org/10.1016/j. jviromet.2005.08.013

Smith EM, Estes MK, Graham DY, Gerba CP (1979). A plaque assay for the simian rotavirus SA11. J. Gen. Virol. 43, 513-519. http://dx.doi.org/10.1099/0022-1317-43-3-513

Sood DK, Aggarwal RK, Kumar S, Sokhey J (1995): A rapid test for measuring the infectivity of Yellow Fever vaccine. Vaccine 13, 427-428. http://dx.doi.org/10.1016/0264410X(94)00035-L

Tate JE, Burton AH, Boschi-Pinto C, Steele AD, Duque J, Parashar UD (2012): 2008 estimate of worldwide rotavirusassociated mortality in children younger than 5 years before the introduction of universal rotavirus vaccination programmes: a systematic review and meta-analysis. Lancet Infect. Dis. 12, 136-141. http://dx.doi.org/10.1016/ $\underline{\text { S1473-3099(11)70253-5 }}$

Wang MQ, Yu L, An H, Cui Y, Han P, Bao H, Kou GY, Zhou X (2012): Comparison of fluorescent focus assay and TCID50-ELISA method for detecting infection titer of trivalent rotavirus reassortant vaccine. Chin. New Drug J. 21, 1166-1169.

Zeng CQ, Estes MK, Charpilienne A, Cohen J (1998): The N terminus of rotavirous VP2 is necessary for encapsidation of VP1 and VP3. J. Virol. 72, 201-208. 